\title{
EARLY ENGLISH BOATS
}

\author{
ROY SWITSUR \\ Godwin Laboratory, Cambridge University, Free School Lane \\ Cambridge, England
}

\begin{abstract}
ABSTRTACT. A large number of early boats discovered in the waterways of England are presently displayed in museums and as public monuments. In some cases conservation practices have caused problems in the radiocarbon dating of these otherwise undated artifacts. Specimen pretreatments are described and the chronology of the boats in different regions of England are presented with approximate calibration to calendar date ranges.
\end{abstract}

\section{INTRODUCTION}

To the early nomadic people from central Europe, the area which now constitutes the British Isles, appeared on the western horizon as a low hilly landscape on the edge of the continent. From the central European plain, the journey was reassonably easy, the way being low lying and marshy, but the country ahead was attractive, tree covered and lush. By 8500 BP or thereabouts, the journey became more difficult as the rising sea level cut off the region from the continental mainland. Further exploitation required transportation across the narrow sea by boats. Penetration into this wooded area would have been far easier using the numerous rivers and streams than journeying by land. Such water craft must always have been important for transport, trade and exploitation of the environment. The timber required for building these small vessels was abundantly at hand and many such craft in the form of rafts, dugout canoes and planked boats in addition to boats, such as coracles, covered with animal skins, undoubtedly would have been made. However, because of the frail organic nature of these boats, once abandoned, or wrecked, they would either rapidly decay, or possibly be reused or probably burned in antiquity. In order to have survived for this investigation, the craft must have been buried rapidly and anaerobic conditions established and maintained until the present time. The sites where they might be preserved are not of the kind likely to attract the normal archaeological study. Hence, until relatively recently, little has appeared in the archaeological literature concerning these boats, their design, construction or use.

There appears to have been only three major reviews of the early boats of England and Wales. Fox (1926) placed the then known monoxylous craft into five classes based on morphological features. It was not until 40 years later that Graham (1966) produced a catalogue of the dugout canoes preserved in British museums and included some of the first reliable diagrams. McGrail (1978) made the most exhaustive and reliable study of the logboats of England and Wales and produced in his thesis a definitive catalogue of known finds with scale diagrams, photographs and references. 
Because of the special conditions surrounding their preservation, an indication of the ages of these boats by means of associated finds or stratigraphy is not reliable and estimates based on stylistic grounds are not yet possible. There is a widespread mythology surrounding logboats that they are essentially "prehistoric" and the work of early man. It has been suggested that following the introduction of metal tools which could be used for fashioning planks, the construction of dugout boats would cease. Nevertheless, reports in local archives and newspapers indicated that logboats of this kind continued to be built and used in Ireland and Scotland at least until the 17th or 18th centuries and in parts of continental Europe until the present century. The general condition of the vessels together with lack of bark or sapwood seems to make dendrochronology of less practical use for these objects than at first imagined, so that, thus far, the chronology for the boats has depended on radiocarbon measurements. ${ }^{14} \mathrm{C}$ determinations of several early craft from England and other regions of Europe have been published and reviewed (McGrail \& Switsur, 1975; McGrail, 1978; McGrail \& Switsur, $1979 \mathrm{a}, \mathrm{b}$ ), and these have shown that some of the boats originate as late as the Medieval period. This paper presents the calibrated date ranges for the earlier determinations together with results that I have obtained subsequently. It is primarily concerned with work carried out at Cambridge and is not intended to constitute a literature survey.

\section{DISCOVERY AND CONSERVATION}

Most of the boats studied were discovered during the past century. Often, they were found during civil engineering work on dredging or straightening waterways. Others were discovered during periods of extended drought when lake or river levels were abnormally low, thus exposing the boats to view. The boats were rescued and often placed on public display either out of doors or in local museums. Usually, they were allowed to dry out slowly and the water loss lessened by covering with sand, straw or bracken, but inevitably there were distortions and many cracks appeared. In an attempt to minimize these effects, primitive techniques at conservation were applied, and where these proved ineffectual, cosmetic preparations were used to enhance the general appearance of the displays. Thus, in many instances, large quantities of glycerol or raw linseed oil were applied liberally to the boats during considerable periods to replace the water and prevent shrinkage and decay. The cracks that did form were filled with molten paraffin wax which was colored with "Berlin" or "Brunswick" black. This dye is a suspension of finely divided carbon, "carbon black," in an organic liquid, usually turpentine oil. After solidification, this was brushed to help it take on the sheen and appearance of wood 'black with age.' Sometimes other mixtures were used, such as "carbolinium," and more recently, epoxy resins, such as "Araldite" mixtures. Other conservation measures were adopted but records of the substances used were not often kept. While these precautions may be admired from the point of view of public display, and indeed the more modern impregnation of large wooden objects with PEG and other polymers is the extension of this early 
work, the use of such carbon-containing materials is somewhat detrimental to ${ }^{14} \mathrm{C}$ dating.

Contamination that was added to the boats in such large quantities contains carbon of disparate origins and ages. Glycerol was probably produced during the saponification of animal fats and so had carbon contemporary with the preservation date and with a greater ${ }^{14} \mathrm{C}$ concentration than the wood of the boat. Linseed oil would also be contemporaneous with the preservation date since it is obtained from growing flax. Likewise, turpentine oil is a natural product from the Pinus tree and so would also contain modern carbon. Paraffin wax, however, could have been produced as a side-product of the mineral oil industry or, more likely, half a century or more ago, by dry distillation of ozokerite or even bituminous shale or lignite. Thus, it is certain that this carbon would be radioactively "dead." The age of the carbon in the "carbon-black" would depend on its method of manufacture. It might have been produced from natural methane or by the combustion of turpentine, or other oil, in a limited air supply and the collection of the soot thus formed, on a cold surface. Hence, this ingredient could be either contemporary or ancient and could vary in different boats. The lack of documentary evidence from museum records makes it difficult to specify the contaminants in any particular logboat. Natural contaminants would also be dependent on the local environment in which the boat had been preserved.

\section{SAMPLE PREPARATION}

To obtain a reliable ${ }^{14} \mathrm{C}$ age for the wood, natural and added impurities must be removed or at least reduced to a very low level. The following procedure was developed and appeared to be effective for most of the specimens. First, the wood was cleaned thoroughly with a brush and vacuum cleaner to remove as much superficial dust and debris accumulated during storage either in the museum or in an open-air display. It was then cut into small pieces and boiled in distilled water for several days with frequent changes of water. The paraffin wax melted during this procedure and much of it floated to the top where it was decanted. The glycerol tended to dissolve in the hot water and was thus also removed during decantation. Several times the mixture was subjected to ultrasonic vibration to shake out the carbon black, some of which became suspended in the hot water. After a few days treatment, when the water remained clear, the wood chips were dried in an oven. They were then placed in a hammer mill and reduced to a powder, ca 250 to $500 \mu$. This was next extracted with organic solvents in a Soxhlet for ca 2 days, followed by 1 day using water as the solvent. This removed the remainder of the glycerol and carbon black. The purified wood was then treated in the normal manner with dilute sodium hydroxide and then acid to remove any humic or fulvic substances. The specimens were further treated to extract the cellulose using Green's (1963) method of chlorite oxidation followed by solubilization in Schweitzer's reagent (cuprammonium hydroxide) and re-precipitation. The specimens of purified cellulose thus produced were washed thoroughly and vacuum-oven dried prior 
to oxidation in the combustion bomb (Switsur, 1973). The preparation was modified for materials other than the wood used in some of the studies.

It was important to obtain wood specimens as near to the bark as possible, so that the time as close to the use of the boat could be determined. This was sometimes difficult to ascertain; thus, some of the ages may be too early. In some instances in earlier determinations, the in situ position of the sample in the boat is not recorded and in some cases, too, wood found close to the boat was measured, rather than that of the boat timber itself. Providing such timber was a patch to cover a split in the boat, this might well give an age for the use of the vessel, if young wood was used, but the accidental proximity of a totally unrelated piece of wood must also be considered, as well as the re-use of ancient wood. In the case of the 'sewn' boats (see below) it was possible to use materials such as thin yew withies and moss which would be renewed during the lifetime of the boat and hence likely to date the final stage of use.

\section{DISCUSSION}

The majority of the vessels considered in this paper are of the type known as monoxylous craft or "logboats," ie, boats made from a single tree trunk. Even logboats vary greatly in size and character, eg, the length of the Brigg boat was almost $15 \mathrm{~m}$ whereas the Giggleswick Tarn boat was $<2.6 \mathrm{~m}$. Some boats kept the simple trunk outline, whereas others had been shaped and provided with rudders, beaks, washstrakes or transoms giving a variety of configurations depending on their purpose. Some were designed to carry people at speed and others were cargo carriers. An aim of this ongoing project is to study the development of the various features and styles of the craft and their temporal and geographic coverage.

Four of the vessels, "sewn" boats, are very different from the logboats and all are from the same part of England. Three (and recently yet another) were discovered in a tidal stretch of the River Humber at North Ferriby, near Kingston on Hull and another in the River Ancholme, a tributary to the Humber, at Brigg. The Brigg boat was discovered in 1888 and described then as a "raft." After excavation and brief study (Thropp, 1887) the site was backfilled. The boat was re-excavated (McGrail, 1975) using modern techniques. The "raft" consisted of a series of thin parallel, oak strakes, the long edges of which had been shaped and numerous small holes drilled. The planks were fastened together by sewing through the holes with pliable withies and moss caulking was applied to make the joints water tight. Cleats were carved in each of the planks to take thin cross members so that the boat could be linked together. The vessel had collapsed flat under the weight of the surrounding clay; hence, the name "raft," but in use, the strakes would have been pulled into a boat shape by the cross timbers. A study (Switsur, 1981) of the ages of different parts of the boat timbers was made as well as that of the environmental materials associated with the structure. The pooled age of the determinations for the Brigg boat, after calibration, yields a date range of $815-790 \mathrm{cal} B C$ with a $95 \%$ probability. This precision is due to several close ages and the shape of the calibration curve in this region. 
Although of different design, the boats from North Ferriby all had a similar "sewn" construction. Two were discovered in 1937 and 1941 by Wright and excavated in 1946 (Wright \& Wright, 1947). Later, the third boat was excavated (Wright \& Churchill, 1965) and, more recently, fragments of a fourth have come to light (Switsur \& Wright, in press). The preliminary ages for three of the boats were determined on timber that was not directly connected. It is now believed that some of these ages should be discounted since the sample pretreatment was possibly imperfect and may have led to falsely early ages. Only determinations made with improved pretreatment techniques using actual boat timbers or caulking materials should be regarded as reliable. Considering the close geographic proximity and similar style of the "sewn" boats, it is tempting to hypothesize that they were all enveloped in a catastrophic event, such as a tidal wave entering the

TABLE 1

Logboats from the north of England

\begin{tabular}{|c|c|c|c|c|c|}
\hline \multirow[b]{2}{*}{ Q-no. } & \multirow[b]{2}{*}{ Boat } & \multirow[b]{2}{*}{${ }^{14} \mathrm{C}$ age $\mathrm{BP}$} & \multicolumn{2}{|c|}{ Calibrated date ranges } & \multirow{2}{*}{$\begin{array}{c}\mathrm{Cal} \\
\mathrm{AD} / \mathrm{BC}\end{array}$} \\
\hline & & & $68 \%$ probability & $95 \%$ probability & \\
\hline 3130 & Smallborough & $520 \pm 45$ & $1390-1440$ & $1335-1460$ & $\mathrm{AD}$ \\
\hline 1495 & Oakmere & $560 \pm 40$ & $1370-1405$ & $1280-1440$ & $\mathrm{AD}$ \\
\hline 1245 & Giggleswick Tarn & $615 \pm 40$ & $1275-1385$ & $1255-1405$ & AD \\
\hline 3049 & Giggleswick Tarn & $690 \pm 40$ & $1255-1285$ & $1250-1380$ & $\mathrm{AD}$ \\
\hline 3126 & Kentmere & $740 \pm 35$ & $1250-1265$ & $1220-1270$ & AD \\
\hline 1390 & Arpley Meadows & $760 \pm 60$ & $1220-1265$ & $1150-1295$ & $\mathrm{AD}$ \\
\hline 1395 & Walton Arches & $860 \pm 60$ & $1040-1230$ & 1015-1265 & $\mathrm{AD}$ \\
\hline 1456 & Irlam & $865 \pm 40$ & $1045-1220$ & $1030-1245$ & $\mathrm{AD}$ \\
\hline 1393 & Fairclough & $880 \pm 60$ & $1035-1220$ & $1010-1260$ & AD \\
\hline 1396 & Barton & $920 \pm 65$ & $1015-1190$ & $985-1240$ & $\mathrm{AD}$ \\
\hline 1391 & Walton Lock & $930 \pm 50$ & $1015-1150$ & $995-1220$ & $\mathrm{AD}$ \\
\hline 3051 & Chirbury 1 & $930 \pm 40$ & $1020-1140$ & $1005-1210$ & AD \\
\hline 1457 & Astbury & $980 \pm 50$ & 995-1045 & $960-1150$ & AD \\
\hline 1394 & Arpley & $990 \pm 65$ & $975-1045$ & $890-1165$ & $\mathrm{AD}$ \\
\hline 1247 & Chirbury 1 & $1000 \pm 50$ & $980-1030$ & $955-1130$ & AD \\
\hline 1392 & Howley & $1075 \pm 60$ & $885-1005$ & $870-1030$ & $\mathrm{AD}$ \\
\hline 1386 & Banks & $1120 \pm 45$ & $875-970$ & $835-1000$ & $\mathrm{AD}$ \\
\hline 3132 & Thornaby & $1265 \pm 40$ & $670-805$ & $655-880$ & $\mathrm{AD}$ \\
\hline 1248 & Knockin & $1270 \pm 45$ & $665-800$ & $650-880$ & $\mathrm{AD}$ \\
\hline 3131 & Ryton & $1340 \pm 50$ & $645-685$ & $610-790$ & $\mathrm{AD}$ \\
\hline 1379 & Ryton & $1410 \pm 40$ & $605-660$ & $590-670$ & $\mathrm{AD}$ \\
\hline 1496 & Baddiley Mere & $1980 \pm 50$ & $40 \mathrm{cal} B C-65 \mathrm{cal}$ AD & 100 cal BC-110 cal AD) & \\
\hline 3050 & Ellesmere & $2260 \pm 45$ & $405-275$ & $410-200$ & $\mathrm{BC}$ \\
\hline 1246 & Ellesmere & $2320 \pm 50$ & $415-390$ & $465-275$ & $\mathrm{BC}$ \\
\hline 1497 & Blae Tarn & $2550 \pm 50$ & $810-700$ & $825-530$ & BC \\
\hline 288 & Branthwaite & $3520 \pm 100$ & $1980-1750$ & $2135-1610$ & $\mathrm{BC}$ \\
\hline 3053 & Branthwaite & $3545 \pm 50$ & 1945-1795 & $2025-1780$ & $\mathrm{BC}$ \\
\hline
\end{tabular}


Humber and her side valleys early in the transition to the Subatlantic period. This would account for their preservation in the anoxic conditions of the clay and mud deposition. The age for the Brigg boat and her environmental samples would not be inconsistent with this hypothesis. The age of

TABLE 2

Logboats from the south of England

\begin{tabular}{|c|c|c|c|c|c|}
\hline \multirow[b]{2}{*}{ Q-no. } & \multirow[b]{2}{*}{ Boat } & \multirow[b]{2}{*}{${ }^{14} \mathrm{C}$ age $\mathrm{BP}$} & \multicolumn{2}{|c|}{ Calibrated date ranges } & \multirow{2}{*}{$\begin{array}{c}\text { Cal } \\
\mathrm{AD} / \mathrm{BC}\end{array}$} \\
\hline & & & $68 \%$ probability & $95 \%$ probability & \\
\hline 3135 & Oakley Park & $470 \pm 50$ & $1405-1460$ & $1385-1470$ & $\mathrm{AD}$ \\
\hline 1398 & Oakley Park & $525 \pm 40$ & $1390-1435$ & $1345-1450$ & $\mathrm{AD}$ \\
\hline 1364 & Cambridge & $535 \pm 45$ & $1380-1430$ & $1300-1450$ & AD \\
\hline 3137 & Hulton Abbey & $545 \pm 40$ & $1375-1415$ & $1295-1445$ & $\mathrm{AD}$ \\
\hline 3038 & Kew & $720 \pm 40$ & $1250-1270$ & $1225-1335$ & $\mathrm{AD}$ \\
\hline 1453 & Kew & $770 \pm 45$ & $1220-1265$ & $1170-1270$ & AD \\
\hline 3127 & North Stoke & $860 \pm 40$ & $1050-1225$ & $1030-1250$ & AD \\
\hline 1387 & North Stoke & $915 \pm 50$ & $1020-1165$ & $1000-1225$ & AD \\
\hline 3052 & Sewardstone & $1070 \pm 45$ & 905-1000 & 875-1025 & AD \\
\hline 3040 & Sewardstone & $1130 \pm 45$ & $875-965$ & $805-990$ & $\mathrm{AD}$ \\
\hline 1454 & South Stoke & $1150 \pm 90$ & $790-970$ & $660-1025$ & $\mathrm{AD}$ \\
\hline 1455 & Burpham No. 1 & $1200 \pm 40$ & $790-885$ & $730-890$ & $\mathrm{AD}$ \\
\hline 3139 & Burpham No. 1 & $1245 \pm 45$ & $680-850$ & $655-885$ & AD \\
\hline 3041 & Walthamstow & $1255 \pm 40$ & $675-810$ & $655-885$ & $\mathrm{AD}$ \\
\hline 3128 & South Stoke & $1275 \pm 35$ & $665-790$ & $650-840$ & $\mathrm{AD}$ \\
\hline 3140 & Amberley No. 1 & $1290 \pm 50$ & $655-790$ & $645-875$ & $\mathrm{AD}$ \\
\hline 828 & Amberley No. 3 & $1310 \pm 70$ & $650-790$ & $605-880$ & $\mathrm{AD}$ \\
\hline 1388 & Walthamstow & $1335 \pm 45$ & $650-685$ & $620-785$ & $\mathrm{AD}$ \\
\hline 3138 & Hardham No. 1 & $1530 \pm 45$ & $450-595$ & $415-610$ & $\mathrm{AD}$ \\
\hline 1244 & Hardham No. 1 & $1575 \pm 50$ & $410-535$ & $380-600$ & $\mathrm{AD}$ \\
\hline 3042 & Walton & $1585 \pm 50$ & $405-530$ & $370-575$ & AD \\
\hline 827 & Hardham No. 2 & $1655 \pm 50$ & $325-425$ & $235-505$ & AD \\
\hline 1399 & Wisley & $1780 \pm 45$ & $195-255$ & $110-345$ & $\mathrm{AD}$ \\
\hline 1389 & Woolwich & $1990 \pm 50$ & $45-55$ & $110-105$ & $\mathrm{BC}$ \\
\hline 3039 & Woolwich & $2070 \pm 45$ & $145-35$ & $205-10$ & $\mathrm{BC}$ \\
\hline 3125 & Glastonbury & $2095 \pm 45$ & $185-60$ & $210-30$ & $\mathrm{BC}$ \\
\hline 1563 & Glastonbury & $2120 \pm 50$ & $205-90$ & $340-30$ & $\mathrm{BC}$ \\
\hline 1375 & Clifton No. 2 & $2175 \pm 50$ & $340-175$ & $400-95$ & $\mathrm{BC}$ \\
\hline 1473 & Holme Pierrepont & $2220 \pm 55$ & $400-200$ & $410-135$ & $\mathrm{BC}$ \\
\hline 821 & Poole Harbour & $2245 \pm 50$ & $405-250$ & $410-190$ & $\mathrm{BC}$ \\
\hline 1374 & Clifton No. 1 & $2250 \pm 45$ & $400-270$ & $410-195$ & $\mathrm{BC}$ \\
\hline 3134 & Clifton No. 2 & $2270 \pm 50$ & $405-280$ & $415-205$ & $\mathrm{BC}$ \\
\hline 357 & Shapwick & $2305 \pm 120$ & $760-220$ & $795-80$ & $\mathrm{BC}$ \\
\hline 3048 & Clifton No. 1 & $2310 \pm 50$ & $410-390$ & $450-270$ & $\mathrm{BC}$ \\
\hline 3129 & Peterborough & $2535 \pm 40$ & $805-635$ & $810-530$ & $\mathrm{BC}$ \\
\hline 1564 & Peterborough & $2610 \pm 50$ & $830-795$ & $875-770$ & $\mathrm{BC}$ \\
\hline 3122 & Chapel Flat Dyke & $3500 \pm 40$ & $1890-1770$ & $1935-1750$ & $\mathrm{BC}$ \\
\hline 3046 & Chapel Flat Dyke & $3590 \pm 60$ & $2035-1825$ & $2135-1775$ & $\mathrm{BC}$ \\
\hline
\end{tabular}


TABLE 3

Boats from the Humber region

\begin{tabular}{rlcccc}
\hline & & & \multicolumn{2}{c}{ Calibrated date ranges } & \multirow{2}{*}{ Cal } \\
Q-no. & Boat & ${ }^{14}$ C age BP & $68 \%$ probability & $95 \%$ probability & Cal \\
\hline 3212 & North Ferriby & $2350 \pm 40$ & $510-385$ & $530-395$ & BC \\
1200 & Brigg & $2545 \pm 100$ & $825-520$ & $910-405$ & BC \\
1499 & Brigg & $2550 \pm 50$ & $810-700$ & $825-530$ & BC \\
1261 & Brigg Raft & $2560 \pm 50$ & $810-770$ & $830-540$ & BC \\
1263 & Brigg Raft & $2570 \pm 60$ & $820-770$ & $845-530$ & BC \\
1257 & Brigg Raft & $2595 \pm 50$ & $825-790$ & $845-660$ & BC \\
1260 & Brigg & $2600 \pm 70$ & $835-790$ & $910-540$ & BC \\
1256 & Brigg Raft & $2605 \pm 50$ & $830-795$ & $850-705$ & BC \\
1199 & Brigg & $2630 \pm 100$ & $890-790$ & $990-450$ & BC \\
1259 & Brigg & $2640 \pm 65$ & $870-800$ & $925-770$ & BC \\
1255 & Brigg Raft & $2655 \pm 50$ & $870-810$ & $920-790$ & BC \\
1258 & Brigg Raft & $2672 \pm 75$ & $915-805$ & $975-780$ & BC \\
1262 & Brigg & $2675 \pm 70$ & $915-810$ & $970-790$ & BC \\
1500 & Brigg & $2720 \pm 50$ & $925-835$ & $980-810$ & BC \\
78 & Brigg Logboat & $2784 \pm 100$ & $1045-840$ & $1245-800$ & BC \\
79 & Short Ferry & $2795 \pm 100$ & $1100-845$ & $1255-805$ & BC \\
3047 & North Ferriby III & $2945 \pm 40$ & $1255-1130$ & $1285-1015$ & BC \\
3045 & North Ferriby III & $2975 \pm 45$ & $1285-1140$ & $1370-1040$ & BC \\
3043 & North Ferriby I & $2980 \pm 55$ & $1280-1130$ & $1375-1010$ & BC \\
3124 & North Ferriby I & $3020 \pm 40$ & $1355-1230$ & $1415-1150$ & BC \\
80 & Appleby & $3050 \pm 80$ & $1425-1220$ & $1515-1060$ & BC \\
1462 & Appleby & $3080 \pm 60$ & $1425-1280$ & $1515-1205$ & BC \\
3044 & North Ferriby II & $3095 \pm 40$ & $1425-1320$ & $1445-1275$ & BC \\
3123 & North Ferriby II & $3120 \pm 45$ & $1435-1345$ & $1520-1290$ & BC \\
3133 & Appleby & $3135 \pm 40$ & $1445-1410$ & $1525-1315$ & BC \\
\hline
\end{tabular}

TABLE 4

Logboats from Wales and Scotland

\begin{tabular}{llrccc}
\hline & & & \multicolumn{2}{c}{ Calibrated date ranges } & \multirow{2}{*}{ Cal } \\
Q-no. & Boat & ${ }^{14}$ C age BP & $68 \%$ probability & $95 \%$ probability & Cal \\
\hline 1243 & Lyn Lyddaw & $640 \pm 50$ & $1260-1380$ & $1250-1405$ & AD \\
3143 & East Greens & $860 \pm 50$ & $1045-1225$ & $1025-1260$ & AD \\
3136 & Llandriddod Wells & $915 \pm 40$ & $1025-1155$ & $1010-1220$ & AD \\
857 & Llyn Llangorse & $1135 \pm 60$ & $870-965$ & $770-1005$ & AD \\
3142 & Kinnordy & $1215 \pm 45$ & $760-850$ & $670-890$ & AD \\
3121 & Loch Errol & $1465 \pm 40$ & $550-625$ & $515-650$ & AD \\
3141 & Loch Errol & $1520 \pm 45$ & $490-600$ & $420-620$ & AD \\
\hline
\end{tabular}


logboats from the same valley would give additional credence to this supposition. An assessment of these measurements has been prepared (Switsur \& Wright, 1989 in press).

\section{CONCLUSION}

The major part of this study has been concerned with logboats recovered at different times during the past century. The results will be considered in detail in other publications, but general conclusions may be drawn. The ages of the logboats cover a wide range from a few hundred years back to ca $3500 \mathrm{yr}$. Virtually all of the surviving boats were constructed from oak trunks. Such lengthy survival appears to be characteristic of this species. Many other types of tree were probably used for boat building, since they would be easier to work than oak. However, conditions have not been suitable for long-term survival. Tables $1-4$ show the ${ }^{14} \mathrm{C}$ ages and calibrated dates (Stuiver \& Pearson, 1986; Pearson \& Stuiver, 1986) for the craft, by region, loosely from the north and the south of the country but with separate tables for the boats from the Humber region and a few examples from Wales and Scotland. A future study of the temporal development of various logboat structural features is planned.

\section{ACKNOWLEDGMENTS}

I wish to thank many of my colleagues for helpful discussions during this study but particularly Sean McGrail, Alan Ward and Ted Wright for help in collecting, recording and processing the material and numerous museum curators for allowing samples to be taken from their exhibits.

\section{REFERENCES}

Fox, C, 1926, Dug-out canoe from South Wales: with notes on the chronology, typology and distribution of monoxylous craft in England and Wales: Antiquaries Jour, v 6, p 121-151.

Graham, J M, (ms) 1966, The dugout canoes of the British Isles: M Sc dissert, Univ Cardiff.

Green, J W, 1963, Wood cellulose, in Whistler, R L, ed, Methods in carbohydrate chemistry, v 3: New York, Academic Press, p 9-21.

McGrail, S, 1975, Brigg raft re-excavated: Lincolnshire Hist \& Archaeol, v 10, p 5-13.

(ms) 1978, Logboats of England and Wales: Ph D dissert, Univ London.

McGrail, S and Switsur, V R, 1975, Early British boats and their chronology: Internatl Jour Nautical Archaeol, v 4, p 191-200.

1979a, Medieval logboats of the River Mersey - A classification study, in McGrail, S ed, Medieval ships and harbours in northern Europe: BAR Internatl, ser, v 66 , p 93-116.

1979b, Medieval logboats: Medieval Archaeol, v 23, p 229-232.

Pearson, G W and Stuiver, M, 1986, High-precision calibration of the radiocarbon time scale 500-2500 BC, in Stuiver, M and Kra, RS, eds, Internatl ${ }^{14} \mathrm{C}$ conf, 12th, Proc: Radiocarbon, v 28, no. $2 \mathrm{~B}, \mathrm{p} 839-862$.

Stuiver, M and Pearson, G W, 1986, High-precision calibration of the radiocarbon time scale, AD 1950-500 BC, in Stuiver, M and Kra, R S, eds, Internatl ${ }^{14} \mathrm{C}$ conf, 12th, Proc: Radiocarbon, v 28, no. 2B, 805-838.

Switsur, V R, 1973, Combustion bombs for radiocarbon dating, in Rafter, T A and GrantTaylor, T L, eds, Internatl conf on ${ }^{14} \mathrm{C}$ dating, 8th, Lower Hutt, Royal Soc New Zealand, v 1, p 11-23. 
Switsur, V R, 1981, Radiocarbon dates for the Brigg raft, in McGrail, S, ed, The Brigg raft and her prehistoric environment: Natl Maritime Mus Archives, ser 6, p 117-121.

Switsur, V R and Wright, E V, in press, Radiocarbon ages and calibrated dates of the boats from North Ferriby, Humberside - A reappraisal: Archeol Jour.

Thropp, J J, 1887, An ancient raft found at Brigg, Lincolnshire: Architectural Soc Repts Papers, v 19, p 95-97.

Wright, E V and Churchill, D M, 1965, The boats from North Ferriby, Yorkshire, England: Proc Prehist Soc, v 31, p 1-24.

Wright, E V and Wright, C W, 1947, The prehistoric boats from North Ferriby, East Yorkshire: Proc Prehist Soc, v 13 p 114-138. 